\title{
Local Wisdom to Creative Cultural Tourism Activity
}

\author{
Tharanee Nawatnatee, Noppamash Suvachart \\ Khon Kaen University, Khon Kaen, Thailand
}

\begin{abstract}
This research is an experimental research survey with the purpose of studying the cultural tourism activity originated from "local wisdom” within Phra Nakhon Si Ayutthaya province in Thailand to be applied as a creative cultural tourism activity. The population of this study comprises 305 Thai and foreign tourists, divided into two groups, namely, 205 tourists as a sampling survey group and 100 tourists as an experimental group. The research tools used are a questionnaire and designed satisfaction assessment. The data were analyzed through the frequency, percentage, mean, standard deviation test, $F$-test, $t$-test, and one-way analysis of variance (ANOVA) with the statistical analysis program. The study showed that the appropriate activities applied from a local wisdom chosen by tourists to be studied were 10 from 20 activities through the questionnaire for ranking the piquancy of each activity from the tourist group. All the 10 activities were studied in this experimental research within the sampling group which consists of Thai and foreign tourists by allowing them to practice in a real situation and assessing their satisfaction in each activity. The assessment reveals that these 10 activities were considered to be interesting and the satisfaction level was extremely high, indicating that the activity applied from the local wisdom studied in this research is appropriate to be used as a creative cultural tourism activity in Phra Nakhon Si Ayutthaya province later in the future.
\end{abstract}

Keywords: local wisdom, creative, cultural tourism activity

\section{Introduction}

Phra Nakhon Si Ayutthaya province is located in the middle region of Thailand. It was a former capital with the longest duration of 417 which was announced as a world heritage city by the United Nations Educational, Scientific, and Cultural Organization (UNESCO) on December 13, 1991. Therefore, Phra Nakhon Si Ayuttaya province has become a famous tourism city with an endless flow of tourists around the world and could be claimed as the top tourist destination of Thailand. Because of the outstanding features in its history, historic sites, historic artifacts, unique architectures, and aged traditions, the tourism form in Phra Nakhon Si Ayutthaya province is emphasized on a sightseeing tourism in some specific tourist destinations, which results in the exceeded concentration of tourists in some certain areas and brings about the monotonousness, contrast to the current tourism direction which focuses on the exchange of idea, knowledge, and experience between the tourists and residents through the conversation and participation in a real situation that can also add the value of history, culture, community lifestyle, and unique location (Saengsanit, 2010). The increasing current tourists are the group which has a strong intention to study the real and true culture of the destination where they visit to create other inspirations. Such an idea is becoming more and more important in terms of the relationship among various stuff caused by the different tourism inspirations (Richards \& Wilson, 2006). The crucial issue is the 
need for participation in a "true" tourism experience which is a new trend of tourism by focusing on the true or original experience that can considerably stimulate the need for tourism experience among the tourists, because the former characteristic of the tourism cannot express the true experience properly (MacCannell, 1976) and although tourists might assume that they have received the true tourism experience which might not be original, it is just a reconstructed one from the related concepts, beliefs, and experiences (Cohen, 1988). As a result, it can be assumed that the tourism which can provide a true tourism experience to the tourist can create a unique and outstanding selling point properly, especially in the tourism destination with cultural heritage and local wisdom which can be expanded and value-added or used as a guideline for designing a tourism activity or product later on.

The change in the current tourism and economic situation affects the tourism in Phra Nakhon Si Ayutthaya province negatively with the reduction of both domestic and foreign tourists. As a consequence, the tourism income (Phra Nakhon Si Ayutthaya Provincial Development Plan, 2011-2013) ${ }^{1}$ has decreased and tends to reach a saturation point in tourism in the near future if its selling point is solely emphasized on a "world heritage city". Therefore, the local wisdom heritage of Phra Nakhon Si Ayutthaya province has been considered by tourism business entrepreneurs or related people to create a "tourism activity" which can provide a different cultural tourism and original tourism experience to tourists. This can be done by applying and developing the available local wisdom in terms of adding-value, distinguishing the tourism activities in the province that were affected by global economic crisis to draw tourist attraction around the world who has an inspiration of studying and participating in local tourism activities to visit Phra Nakhon Si Ayutthaya province. In conclusion, this tourism improvement can respond to the need of inspired tourists and can contribute to a sustainable condition in the future.

\section{Literature Review}

\section{Culture-Based Tourism}

Culture-based tourism is a kind of sightseeing tour with the purpose of studying the unique culture and tradition in a particular area where the local people participated in such tourism, based on the awareness of environment and local culture reservation, such as a visit of court tradition (royal tradition) or local tradition and a village lifestyle visit (Wongwipak, 2004). The culture-based travelling and tourism, although consisting of various factors, is a crucial base of creative tourism. First, it is a promotion of tourism and cultural heritage. Second, it is a chance for a tourist who is interested in culture to make a decision during or after his/her travel to change the status from a visitor to a participant in each activity (Ohridska-Olson \& Ivanov, 2010). In conclusion, culture-based tourism refers to tourism with the purpose of studying a country or region's culture, in particular the values, history, and lifestyles of local people with a cultural difference, their architectures, arts, religions, beliefs, traditions, festivals, rituals, and wisdom including plays and activities in such communities.

\section{Creative Tourism}

Creative tourism has become an important issue since the expansion of culture-based tourism, together with the fact that the culture-based tourists are experienced and have an intention to gain more tourism experience, whereas each tourist destination needs to find the alternatives besides the original advantage. Therefore, creativity is a crucial factor for tourism, because it can create a condition that can respond to the need of tourists

1 Retrieved from http://gallery.aru.ac.th/ plan/plann/planayttaya.pdf. 
in terms of self-development, a relationship between tourist culture and local residents together with the avoidance of boredom and redundancy. Creative tourism is an extended concept of sustainable tourism, focusing on the tourism that can present a new experience to a tourist. In creative tourism, active participation is important and tourists and local residents must play a role in tourism resources conservation for a long-term benefit. Moreover, creative tourism requires cultural resources such as arts, traditions, lifestyles, and original livings as crucial factors to be blended with a creative concept to form a unique tourism product that can draw a tourist's attention properly. For Thailand which is famous for its tourism and abundant and unique cultural resources, it is possible to gain a benefit from such resources to improve a tourism product and service in order to respond to the needs in the world market, especially in terms of the friendliness and hospitality of Thai people based on the agricultural traditions and Buddhism beliefs. With the blending of the harmonious arts, culture, and local wisdom together with Thai people's friendliness and hospitality, it is possible to enhance a tourism product's quality to draw tourists' attention affectively.

\section{Local Wisdom}

Wisdom is a collection of ideas since the past time. It is about the management of the relationship between humans and things through various traditions, lifestyles, occupations, and rituals to maintain a balance with the purpose of creating happiness among the communities, villages, and individuals. In case of unbalance, there shall be a problem of disorder between such communities and villages. Besides, wisdom can also refer to the occupational experience gained from studies (Yuthakul, 1994), including the knowledge, concepts, beliefs, abilities, and clearness which have been collected within the communities as a guideline for adaptation and living properly in the specific ecology or natural environment, including a cultural environment that has been developed continuously. It can also refer to the knowledge, beliefs, perceptions, abilities, and clearness resulted from the wisdom-based adaptation to the environment where the communities are located (Na Talang, 1997). The local wisdom related to the residents, occupations, lifestyles, hospitalities, and language used has been originated, collected, and used continuously as a local heritage within each community (Thongdee, 1999). In conclusion, it is possible to say that local wisdom is a long-term collection of knowledge, perceptions, abilities, beliefs, and experiences through traditions, norms, and lifestyles with the purpose of creating happiness and balance between human and natural environments together with social culture continuously as a local heritage.

\section{A Tourism Activity and Tourism Experience}

Popular creative tourism at present is originated from the tourism pattern in New Zealand which is a sustainable style that aims to provide the true feelings of local culture through participation in each creative activity like a workshop that can be conducted in a small group at a local lecturer's residence or workplace. This activity shall allow a tourist to find out self-creativeness or gain new experience through a reaction with a local. The creation of activity is done through an informal local culture and focuses on practices within a small workshop where a visitor is allowed to find out his/her self-creativeness and to be harmonious with a local in a more sustainable approach (Raymond, 2007). The study showed that the creativeness and tourism have a fast-growing connection, whereas creative tourism is an explicit reflection of the unity between tourism and different areas defined. Such creativeness can be used as a guideline for a change in the available tourism. Moreover, creative tourism is also another channel for cultural tourism because of its flexibility and true experience provided to tourists and hosts with the awareness of a danger of creativeness and commodification in daily lives (Richards, 2011). 


\section{Methodology}

\section{Sample Groups}

The sample groups of this study consisted of 305 samples which can be categorized into two groups as follows:

The first group: The sample group is chosen through a questionnaire for ranking their interests towards the tourism activities, consisting of 205 people, namely, 162 Thai tourists and 43 foreign tourists;

The second group: The experimental sample group is chosen for assessing their satisfaction levels, consisting of 100 people, namely, 79 Thai tourists and 21 foreign tourists.

\section{Instruments}

The research instruments used are a questionnaire and satisfaction index.

Questionnaire. The questionnaire was divided into three sections:

Section 1: The closed-ended demographic questions of the sample group for collecting the information about their gender, age, educational level, occupation, and monthly average income;

Section 2: The ranking of satisfaction towards tourism activities. In this section, the researchers shall apply the gained information from a literature review and related research to schedule 20 tourism activities, of which, 10 appropriate activities applied from a local wisdom were chosen, and tourists were asked to rank their interests towards the 10 activities by numbering them from 1 to 10 ;

Section 3: Other recommendations in the form of open-ended questions.

Satisfaction index. This process is done by focusing on the specific experimental cultural tourism activities and we divide the satisfaction level into five levels with three sections as follows:

Section 1: The demographic sample group questions;

Section 2: The satisfaction level towards the specific experimental cultural tourism activities participation. In this section, the questions are based on a 5-point Likert scale, ranging from 1 to 5 , where $5=$ Highest, 4 = High, 3 = Average, 2 = Low, and 1 = Least. The 10 activities shall be categorized into three categories as follows: the process/procedure in transfer, the lecturer/demonstrator of wisdom activities, and the appropriateness of the cultural tourism activities;

Section 3: Other recommendations in the form of open-ended questions.

\section{Data Collection}

The data used in this study are secondary data and primary data.

Secondary data collection. It is done through a literature review of related documents, texts, magazines, and researches which focus on the Phra Nakhon Si Ayutthaya local wisdom as a guideline for designing tourism activities or products.

Primary data collection. It is done through the sample group as follows:

(1) The survey research: It is done through the expansion of 205 questionnaires for ranking and choosing the 10 cultural tourism activities as a guideline for real practices;

(2) The experimental research: It is done through the experimental tourism activities where the second sample group can participate, and the researchers also use the 100 satisfaction indexes to assess the participants' satisfaction level towards the activities. 


\section{Data Analysis}

The researchers analyzed the collected data through the questionnaire as a guideline for choosing the interesting tourism activities. Frequency-based method was used for ranking the satisfaction level of tourists towards the 10 tourism activities to be examined and the real practices among the sample group. Descriptive statistics were used to analyze the demographic data through the use of frequency and percentage for describing the individual information.

Contents analysis was used to describe the individual open-ended questions by focusing on the important issues and to present the information in a narrative form together with the descriptive statistics through the use of mean and standard deviation for the analysis of satisfaction level. Finally, the inferential statistics with $t$-test and one-way analysis of variance (ANOVA) (F-test) were used for analyzing the individual differences.

\section{Results}

\section{The Result of the Study of the Local Wisdom Appropriateness as a Model for Culture-Based Tourism Activities in Phra Nakhon Si Ayutthaya Province}

According to the study of local wisdom activities in Phra Nakhon Si Ayutthaya province, it is found that there are many outstanding unique activities such as local handicrafts and local material products; yet, local wisdom craftsmanship has not been enhanced to create value-added tourism, especially the adaptation of local wisdom craftsmanship to design creative tourism activities. Therefore, the researchers collected the famous local wisdom activities within Phra Nakhon Si Ayutthaya province to allow a tourist to participate and choose 10 from 20 activities for the next experimental step. The 10 activities chosen by 205 Thai and foreign tourists in the first sample group reveal that pottery activity was ranked the first by 33 people, which is equal to $16.10 \%$. The second is Thai silk-artificial pineapple making, ranked by 27 people, which is equal to $13.17 \%$. The third is candy floss cooking, ranked by 22 people, which is equal to $10.73 \%$. The fourth is huntra dessert cooking, ranked by 22 people, equaling to $10.73 \%$. The fifth is fish net weaving from leaves, ranked by 17 people, which is equal to $8.29 \%$. The sixth is Thai kite making, ranked by 22 people, which is equal to $10.73 \%$. The seventh is hammock weaving, ranked by 20 people, which is equal to $9.76 \%$. The eighth is artificial flower making from sesbania, ranked by 35 people, which is equal to $17.07 \%$. The ninth is artificial menthol making, ranked by 29 people, which is equal to $14.15 \%$. Finally, the tenth is miniature Thai royal barge carving, ranked by 20 people, which is equal to $9.76 \%$ (see Table 1 ).

Table 1

The Figure and Percentage of the Responses Categorized Through Each Activity

\begin{tabular}{lllc}
\hline No. & Activity & Amount & $\%$ \\
\hline 1 & Pottery & 33 & 16.10 \\
2 & Thai silk-artificial pineapple making & 27 & 13.17 \\
3 & Candy floss cooking & 22 & 10.73 \\
4 & Huntra dessert cooking & 22 & 10.73 \\
5 & Fish net weaving & 17 & 8.29 \\
6 & Thai kite making & 22 & 10.73 \\
7 & Hammock weaving & 20 & 9.76 \\
8 & Artificial flower making from sesbania & 35 & 17.07 \\
9 & Artificial menthol making & 29 & 14.15 \\
10 & Miniature Thai royal barge carving & 20 & 9.76 \\
\hline
\end{tabular}




\section{The Result of the Study of the Tourists' Satisfaction Level Towards the Local Wisdom Cultural Tourism in Phra Nakhon Si Ayutthaya Province}

The result of the study of the second sample group, comprising 100 people through the questionnaire, shows that most responses are from 79 Thai people and 21 foreigners. Most of the respondents are females, in the number of 68, and the rest are 32 males. Most respondents (56 people) are at the age of 20-30, followed by 20 people at the age of 31-40, whereas the fewest responses are from three people who are at the age of 60 . Most respondents (45 people) have a bachelor degree, followed by 29 people with a college degree, whereas the fewest of the respondents have a master degree, in the number of two people. Most respondents, in the number of 38, are students/university students, followed by 27 people who are office employees/staff, whereas the fewest of the respondents are four people who are daily workers/contractors. Most respondents (32 people) have a monthly income lower than 10,000 baht, followed by 31 people with a monthly income of 10,001-20,000 baht, and the fewest of the respondents (three people) have an income of around 40,001-50,000 baht per month.

The satisfaction assessment results show that the respondents are satisfied with the activity in a whole picture at the highest level. Considering the details, it is found that tourists' satisfaction is at the highest level in all activities as shown in Table 2 and Figure 1.

Table 2

The Average and Statistic Deviation Point of Satisfaction Level

\begin{tabular}{lcll}
\hline Activity & $\bar{X}$ & S.D. & Satisfaction level \\
\hline Fish net weaving & 4.53 & 0.49 & Highest \\
Miniature Thai royal barge carving & 4.50 & 0.40 & Highest \\
Hammock weaving & 4.42 & 0.50 & Highest \\
Thai kite making & 4.59 & 0.49 & Highest \\
Artificial flower making from sesbania & 4.51 & 0.39 & Highest \\
Thai silk-artificial pineapple making & 4.52 & 0.39 & Highest \\
Pottery & 4.64 & 0.46 & Highest \\
Huntra dessert cooking & 4.55 & 0.48 & Highest \\
Candy floss cooking & 4.51 & 0.42 & Highest \\
Artificial menthol making & 4.44 & 0.40 & Highest \\
Total & 4.52 & 0.37 & Highest \\
\hline
\end{tabular}

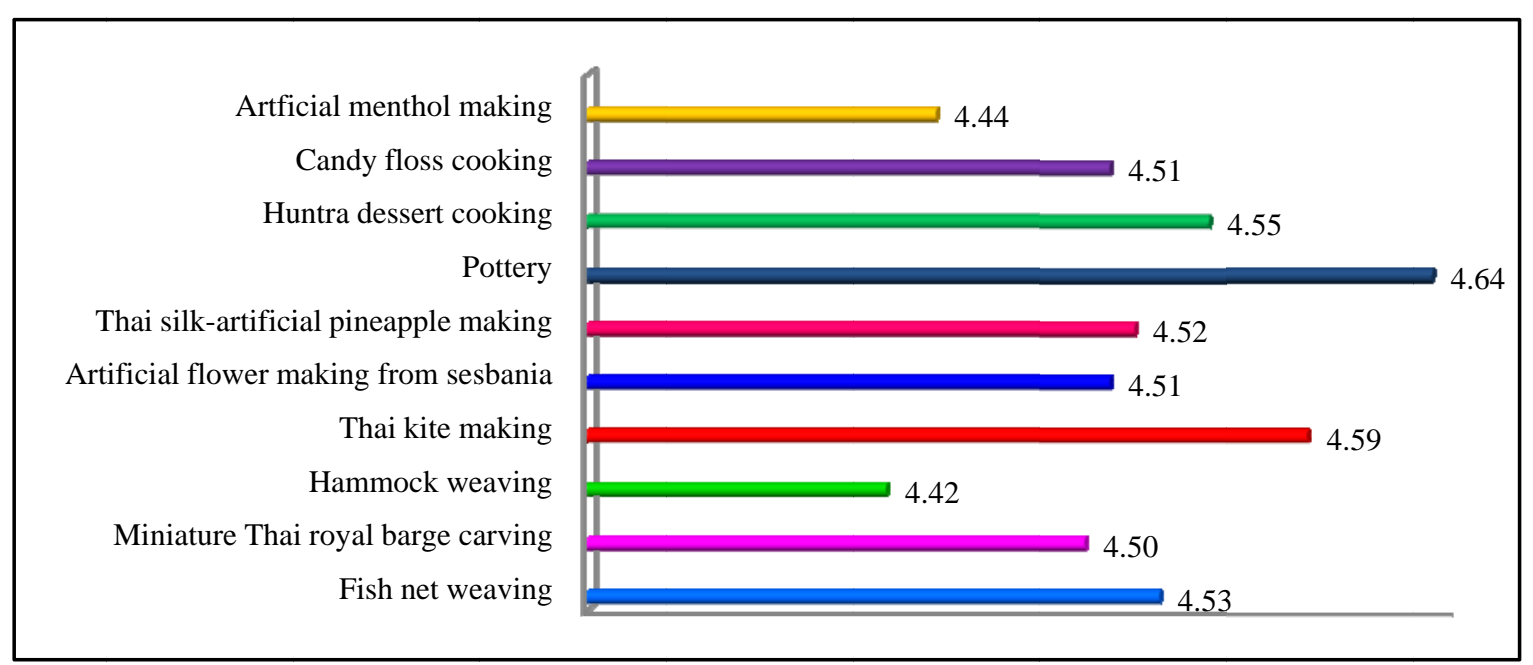

Figure 1. Satisfaction level towards each local wisdom activity. 


\section{Conclusions and Recommendations}

The design of creative tourism based on local wisdom to creative culture-based tourism activities in this study is conducted from the collection of local wisdom in Phra Nakhon Si Ayutthaya province which is widely accepted between tourists and locals, especially the craftsmanship local wisdom and valuable handicrafts, such as weaving, carving, inventing, and famous food cooking. This local wisdom is collected and designed as a tourism activity to express the culture of each area that allows a tourist to learn and feel the true experience through participation together with a reaction with a host. This is assumed to be a change for a host who just only used to be a tourism product manufactured in the past to be a "communicant" for a tourist. The way to design creative culture-based tourism activities is through adding value for a product from local wisdom and providing a true tourism experience to a tourist effectively.

In the end, the researchers of the current study recommend the following:

(1) A tourist agency should apply the cultural tourism activities from this study as a part of the available cultural tour program in Phra Nakhon Si Ayutthaya province for increasing alternative choices for tourists;

(2) Government sections should encourage and support the founding of local wisdom and heritage conservation team by providing an exhibition area of local wisdom activities and a distribution area of local wisdom products as a source for local people's income that focuses on the community's fair benefits and income;

(3) Tourism sections in Phra Nakhon Si Ayutthaya province should publicize various tourism activities in each area by collecting the outstanding local wisdom based tourism activities to be known by tourists. Such publication must be emphasized on any tourism activity which is open to tourists so as for them to be able to participate in each tourism activity, according to a creative tourist who focuses on tourism experience which is popular at present;

(4) On one hand, government sections should set up a provincial tourism database through the collection of various interesting tourism activities in connection with the available cultural tourism. On the other hand, there should be a community tourism center as a learning source of the culture and local wisdom in Phra Nakhon Si Ayutthaya province;

(5) There should be a development program for personnel responsible for tourism activities, such as the language development program, the awareness of being a host, the process of knowledge transfer to a tourist, and the creation of experience among personnel through various appropriate approaches;

(6) A tourism section should set up a plan and provide a proper knowledge of composing a workshop to local people with the purpose of transferring the knowledge of local wisdom as a part of cultural tourism properly.

\section{References}

Cohen, E. (1988). Authenticity and commoditization in tourism. Annals of Tourism Research, 15(3), 371-386.

MacCannell, D. (1976). The tourist: A new theory of the leisure class. New York, NY: Schocken Books.

Na Talang, E. (1997). Local wisdom: Villager's way of life and learning process. Nonthaburi: Sukhothai Thammathirat University Press.

Ohridska-Olson, R., \& Ivanov, S. (2010). Creative tourism business model and its application in Bulgaria. Retrieved from http://ssrn.com/abstract=1690425

Raymond, C. (2007). Creative tourism New Zealand: The practical challenges of developing creative tourism. In G. Richards, \& J. Wilson (Eds.), Tourism, creativity, and development (pp. 145-157). London: Routledge. 
Richards, G. (2011). Creativity and tourism: The state of the art. Annals of Tourism Research, 38(4), 1225-1253.

Richards, G., \& Wilson, J. (2006). Developing creativity in tourist experiences: A solution to the serial reproduction of culture? Tourism Management, 27(6), 1209-1223.

Saengsanit, N. (2010). Creative tourism knowledge. Creative tourism model project (Faculty of Sociology and Anthropology, Thammasat University).

Thongdee, A. (1999). Local history force to community development: A case study of Putthamonthol district community, Nakornpathom province. Nakornpathom: Mahidol University.

Wongwipak, C. (2004). Cultural resources management to sustainable tourism. Nakornpathom, Sanam Chandra Palace Campus: Silpakorn University Printing House.

Yuthakul, P. (1994). Roles of folk healers in E-San countryside society. Khon Kaen, Khon Kaen University: Research \& Development Center. 